\title{
STRONG APPROXIMATION OF SOME ADDITIVE FUNCTIONALS OF SYMMETRIC STABLE PROCESS
}

\author{
M. Ait OuAhra, A. Kissami AND A. SGHir
}

\begin{abstract}
This paper deals with some additive functionals based on the local time of symmetric stable process. In concrete, we obtain some $L_{p}$-inequalities of the local time and the fractional derivative of the local time of symmetric stable process of index $1<\alpha \leqslant 2$. As an application, we generalize the well known Barlow-Yor [4] inequality, which we use to give a strong approximation version, (almost surely estimate), of occupation times problem of this process. Our results generalize those obtained by Csaki et al. [7] for Brownian motion, and Ait Ouahra and Ouali [2] for symmetric stable process of index $1<\alpha \leqslant 2$ in $L_{p}$-norm.
\end{abstract}

Mathematics subject classification (2010): 60J55.

Keywords and phrases: Strong approximation, additive functional, stable process, fractional derivative, local time, Barlow-Yor inequality.

\section{REFERENCES}

[1] M. Ait Ouahra And M. EdDahbi, Théorèmes limites pour certaines fonctionnelles associées aux processus stable sur l'espace de Hölder, Publ. Math. 45 (2) (2001), 371-386.

[2] M. Ait OuAhra AND M. OuALI, Occupation time problems for fractional Brownian motion and some other self-similar processes, Rand. Oper. Stoch. Equa. 17, Issue 1 (2009), 69-89.

[3] M. T. BARLOW, Necessary and sufficient conditions for the continuity of local times of Lévy processes, Ann. Prob. 16 (4) (1988), 1389-1427.

[4] M. T. BARLow AND M. Yor, Semi-martingale inequalities via the Garcia-Rodemich-Rumsey lemma, and applications to local times, J. Funct. Anal. 49 (1982), 198-229.

[5] T. Bojdecki, L. Gorostiza, A. TAlarczy K, Sub-fractional Brownian motion and its relation to occupation times, Statist. Probab. Lett. 69 (2004), 405-419.

[6] E. S. Boylan, Local times for a class of Markov processes, Illinois J. Math. 8 (1964), 19-39.

[7] E. CsAKI, Z. SHI AND M. YoR, Fractional Brownian motions as "higher-order" fractional derivatives of Brownian local times, in: Limit Theorems in Probability and Statistics, I. Balatonlelle, Janos Bolyai Math. Soc., Budapest (2000), 365-387.

[8] E. CSAKI, M. CsÖRgő, A. Földes AND Z. ShI, Path properties of Cauchy's principal values related to local time, Studia. Sci. Math. Hungarica. 38 (2001), 149-169.

[9] P. J. Fitzsimmons AND R. K. Getoon, Limit theorems and variation properties for fractional derivatives of the local time of a stable process, Ann. Inst. H. Poincaré. 28 (2) (1992), 311-333.

[10] M. B. MARCUS AND J. Rosen, p-variation of the local times of symmetric stable processes and of Gaussian processes with stationary increments, Ann. Probab. 20 (4) (1992), 1685-1713.

[11] S. G. SAmko, A. A. Kilbas And O. I. Marichev, Fractional integrals and derivatives. Theory and applications, Gordon and Breach Science Publishers, Yverdon (1993). 